\title{
Development of Environmental Sounds for Auditory Training
}

\author{
Pyohee Ahn, Kyoungwon Lee \\ Department of Audiology, Hallym University of Graduate Studies, Seoul, Korea
}

\section{청능훈련을 위한 환경음원의 개발}

안 표 희·이 경 원

한림국제대학원대학교 청각학과

\begin{abstract}
Purpose: The purpose of this study was to develop one of auditory training tools for people who has difficulty in hearing and understanding speech. This study was designed for an auditory training tool using environmental sounds which can be generally heard in every life. According to this new training tool, various auditory training is generally performed on clinical fields for hearing-impaired people wearing hearing aids or cochlear implants. Methods: Thirty-four adults with normal hearing participated in validity test and they were assigned to two groups by age; twenty young listeners (20-30's) and fourteen elderly (50-60's) listeners. All the environmental sounds were presented up to 4 times at the individual most comfortable level. And the testing paradigm employed was both subjective measures (open-set) and objective measures (closed-set). With the aim of auditory training tool using environmental sounds, all the sound sources satisfied the identification accuracy more than a percentage of eighty. Results: As a result of the test for verification, only 44 pairs of exemplars were adopted as the auditory training tool among a total of 44 sound source pairs. The environmental recognition score by age showed a significant difference between two groups $(p<0.01)$, while the score by list did not. Conclusion: The ultimate purpose of developing this environmental sounds tool was to use it with a substantial auditory training tool on a large number of clinical fields. This tool would be contributed to enhancing communication among hearing-impaired people.
\end{abstract}

Key Words: Hearing impaired, Auditory training, Environmental sound, Hearing aid, Cochlear implant.

\section{INTRODUCTION}

난청이 발생했을 때 보청기의 착용만으로 난청인의 의사소 통의 불편함을 해소하기에는 한계가 있다. 난청인의 의사소통 능력을 개선하기 위해서는 난청인 개개인에게 적합한 형태와 수준, 그리고 지속적이고도 반복적인 청능훈련이 필요하다. Sweetow \& Sabes(2006; 2010)는 의사소통 능력을 향상시키 기 위해서는 청능훈련이 큰 역할을 한다고 밝힌 바 있다. 이 외 에도 다양한 선행연구를 통해 청능훈련이 실제적으로 난청인 의 의사소통 능력의 개선에 미치는 효과를 확인할 수 있는데 Burk \& Humes(2008), Cho et al.(2013), Kwon(2014), Lee (2011), Yeo et al.(2014)의 연구에서는 난청인에게 청능훈련을 실시했을 때 소음 하에서 어음 또는 문장인지도의 향상이 있
었음을 보고하였다.

청능훈련은 어음(speech sound)과 환경음(environmental sound)을 도구로 사용할 수 있다. 그중에서 환경음은 일상생활 에서 접할 수 있는 여러 가지 종류의 소리를 총칭하는 것으로 어음과는 달리 다양한 음원의 정보를 포함하고 있기 때문에 그 소리 자체만으로도 중요한 의미를 지닌다. 환경음의 높은 인지 능력은 주변 환경에 대한 적응을 도울 뿐 아니라 예상치 못한 돌발상황을 인지하고 즉각적으로 반응할 수 있게 한다. 특히 보 청기나, 인공와우를 착용한 난청인의 경우 그 영향은 더욱 중요 하며, 배경소음과 환경음을 분별해 냄으로써 일상생활에서 보 다 많은 소리에 대한 정보를 제공받을 수 있다. 환경음인지도는 어음인지도와의 상관관계를 보이는데 이는 환경음을 처리하는 복합적인 과정이 어음을 인지하는 방법과 공통적인 요인을 포 
함하고 있기 때문이다(Shafiro et al., 2011). Reed \& Delhorne(2005)은 80 94\%의 높은 환경음인지도(evironmental sound recognition score)를 가진 피검자는 그렇지 않은 피검자 에 비해 높은 어음인지 능력을 나타내어 환경음인지도와 단어 인지도 간에 연관성을 보고한 바 있다. 또한 Inverso \& Limb (2010)는 조음구조와 시간적 단서가 어음과 비슷한 환경음 일 수록 높은 인지도를 갖는 것을 근거로 하여 환경음 인지능력의 향상이 어음인지의 개선에 미치는 긍정적 상관관계를 밝혔으 며 비언어적인 임상적 청능훈련도구 개발의 중요성을 함께 강 조하였다. 국내의 연구에서 Lee \& Kim(2011)은 인공와우 및 보청기를 착용한 난청인을 대상으로 단음절과 환경음의 인지 도를 분석한 결과 환경음인지도가 우수한 난청인일수록 단어 인지도 또한 높게 나타남을 보고하였다. 그리고 Shafiro(2008) 는 반복적인 청능훈련을 통해 환경음 지각에 향상을 가져올 수 있다는 사실을 설명하였는데 훈련 전 $33 \%$ 의 평균 환경음인지 도가 청능훈련 후 $63 \%$ 까지 상승했음을 보고하였다. 해당 연구 의 피검자는 훈련에 사용된 환경음은 물론 익숙하지 않은 비훈 련용 환경음의 인지에 있어서도 괄목할 만한 개선을 보였다고 하였다.

선행 연구를 종합해 보면 환경음을 이용한 반복적인 청능훈 련은 궁극적으로 보청기 또는 인공와우 착용인의 어음인지 향 상에 도움을 주어 의사소통 능력의 개선을 가져오며, 이에 따 라 난청인의 삶의 질 개선에 긍정적인 역할을 기대할 수 있을 것이다. 따라서 어음과 더불어 환경음을 이용한 청능훈련 도구 및 훈련 프로그램의 개발은 매우 중요하다. 이에 본 연구에서는 일상생활에서 접하기 쉬운 보편적인 환경음원을 수집한 후 체 계적인 검증을 통해 청능훈련을 위한 환경음원을 개발하고자 하였다. 이를 통하여 보청기, 인공와우 등 증폭기기를 착용한 난청인의 청능훈련에 활용함으로써 난청인의 의사소통 능력을 개선하는 데 기여하고자 하였다.

\section{MATERIALS AND METHODS}

\section{연구 대상}

본 연구에서 청능훈련용 환경음을 선별하기 위해 참여한 대 상자의 수는 20 30대(평균 연령; 30.5세) 20명(남; 10명, 여; 10 명)과 50 60대(평균 연령; 59.1세) 14명(남; 8명, 여; 6명)으로 총 34명이었다. 대상자 모두 육안 관찰 시 외이도와 고막에 이상 소견을 보이지 않았으며, $\mathrm{A}$ 형의 고막운동도를 나타냈다. 평균 순음역치(pure tone threshold average)의 평균은 20 30대 그 룹이 $20 \mathrm{~dB} \mathrm{HL}$ 이하, 50 60대 그룹은 $30 \mathrm{~dB} \mathrm{HL}$ 이하였다. 본 연구에서는 모든 대상자로부터 실험에 대한 동의를 구하였다.

\section{연구 장비}

순음청력의 측정은 전기음향적 보정을 실시한 Grason-Stadler사(Eden Prairie, MN, USA)의 GSI 61 청력검사기(Eden Prairie, MN, USA)와 TDH-50 헤드폰을 사용하여 방음실에 서 진행하였고, 고막운동도 검사는 Amplivox사(Oxfordshire, UK)의 Otowave 102 중이검사기를 사용하였다. 환경음원의 선 정을 위해 평가를 실시한 검사실은 소음수준이 1 분간 측정했 을 때 $40 \mathrm{~dB} \mathrm{~L} \mathrm{~L}_{\mathrm{Aeq}}$ 이하인 방이었다. 그리고 환경음원을 검증하 기 위해 환경음을 노트북에 wave 파일로 저장한 후 $8 \mathrm{Ohm}$ 스 피커를 통하여 피검자에게 제시하였다. 환경음 수집은 Apple 사(Cupertino, CA, USA)의 iPhone ios7을 이용하였으며, 녹음 시 표본화 주파수와 비트는 $22,050 \mathrm{~Hz}$ 와 16비트였다. 그리고 수집한 음원의 편집은 Goldwave 2.0과 Adobe Audition (version 3.0), 주파수 분석은 Kay electronics사(Beaumont, TX, USA)의 CSL (computerized speech lab, model; 4500)을 사 용하였다.

\section{환경음원의 개발 절차}

환경음 훈련도구의 개발은 환경음원의 수집과 편집, $\mathrm{CD}$ 의 제 작, 환경음원의 검증 순으로 진행하였다.

\section{환경음의 수집}

환경음은 일상적으로 가장 빈번하게 들을 수 있는 소리들로 선별하여 수집하였으며, 녹음은 인터넷 웹사이트에서 저작권 없이 다운로드가 가능한 음원을 수집하거나, 유튜브(Youtube) 를 비롯한 다큐멘터리, 영화 등 다양한 영상매체에서 오디오를 발췌하여 편집하였다.

\section{환경음원의 편집과 $\mathrm{CD}$ 의 제작}

환경음의 선택을 위해서 수집한 환경음원의 확장자를 wave 파일로 변환한 후 편집하였다. 음원의 편집은 우선 음원 내에 존재하는 잡음을 최대한 제거한 후, 소리의 특성이 가장 잘 드 러난 부분을 기준으로 최소 2 초에서 최대 5 초의 길이로 음원 의 길이를 조절하였다. 그리고 음원의 진폭을 평균 실효치(root mean square)를 기준으로 동일한 레벨로 조절한 후 음원의 특 징이 골고루 분포하도록 하여 2 개의 목록으로 제작하였다.

\section{환경음 훈련도구의 검증}

환경음 훈련도구의 검증은 수집한 환경음에 대한 인지도의 평가를 실시하여 환경음을 선정한 후 같은 내용을 무작위로 배치한 두 개의 환경음 목록에 대한 차이를 검증하였다. 수집 한 환경음에 대한 평가는 조용한 방에서 청취자가 느끼는 가장 편안한 수준, 즉, 쾌적수준(most comfortable level)에서 최대 네 
번까지 소리를 반복해서 양이를 통해서 들려주었다. 평가 방법 은 세 번째까지 소리를 제시할 때는 보기를 제시하지 않는 개 방형(open-set), 네 번째 소리를 제시할 때에는 그림판을 통해 보기를 제시하는 폐쇄형(closed-set) 검사로 평가하였다. 음원 은 목록1 (list 1)-목록2 (list 2) 순서로 제시하였고 나중에 제시 하는 목록 2 의 정확한 환경음인지도의 평가를 위하여 목록 1 의 정답 여부는 검사가 끝난 후에 알려줌으로써 교육화 및 친숙화 를 방지하였다. 환경음의 선정 방법은 음원을 반복적으로 제시 했을 때 최초에 맞추면 $100 \%$, 두 번째는 $75 \%$, 세 번째는 $50 \%$ 로 점수를 부여했고, 네 번째부터는 그림판을 통해 보기를 제시 하여 맞춘 경우는 $25 \%$, 네 번째도 틀린 경우는 $0 \%$ 의 점수를 부여하였다. 본 연구에서는 평균 환경음인지도가 $80 \%$ 이상인 음원을 청능훈련용 환경음원으로 채택하였으며, 선정한 환경음 목록은 연령대별로 목록 간의 차이를 확인하였다.

\section{분석 방법}

선정 전후 환경음원의 목록 간 그리고 연령대 간의 차이는 각
각 대응표본 $t$-test로 분석하였으며, 사용한 통계 프로그램은 SPSS (version 20.0; SPSS Inc., Chicago, IL, USA)였다.

\section{RESULTS}

\section{수집한 환경음원}

환경음은 일상적으로 가장 빈번하게 들을 수 있는 소리로 교 통수단 8 개, 신체 10 개, 동물 10 개, 실내 환경음 8 개, 실외 환경 음 14 개, 악기 8 개의 소리를 각각 2 가지씩 수집하였다. 그리고 수집한 음원은 청능훈련에 사용하기에 적합한 환경음원을 선 정하기 위해서 Table 1과 같이 목록 1과 목록 2로 구분하여 무 작위로 배치하였다.

\section{수집한 환경음원의 평가}

수집한 환경음원이 도구로서 적합성을 갖는지를 검증하기 위 해 피검자 34 명에게 개방형과 폐쇄형 검사를 통하여 각각의 음 원에 대한 환경음인지도를 알아보았다. Figure 1과 2에서 평균

Table 1. Two lists of environmental sound sources which were collected for verification

\begin{tabular}{|c|c|c|c|}
\hline \multicolumn{2}{|c|}{ List 1} & \multicolumn{2}{|c|}{ List 2} \\
\hline Doorbell & Flute & Door closing & Flute \\
\hline Train running & Whistling-human & Aircraft engines & Clapping \\
\hline Cow & Aircraft engines & Dog barking & Ship whistle \\
\hline Door closing & Wolf & Camera shutter & Duck \\
\hline Coughing & Drilling & Snoring & Vacuum cleaner \\
\hline Bird chirping & Camera shutter & Wolf & Siren \\
\hline Siren & Thunder & Sudden braking-car & Beat box \\
\hline Horse & Frog & Chicken & Cat \\
\hline Clapping & Wind blowing & Screaming & Waves \\
\hline Piano & Car horn & Drum & Car starting \\
\hline Phone rings & Drum & Doorbell & Piano \\
\hline Helicopter & Crumpling PET & Motorcycle & Toilet flushing \\
\hline Chicken & Oriental bell & Horse & Whistle (tool) \\
\hline Toilet flushing & Hair dryer & Hair dryer & Phone rings \\
\hline Elephants & Baby crying & Elephants & Laughing \\
\hline Car starting & Ship whistle & Car horn & Drilling \\
\hline Bowling pins & Zipper & Keyboard & Gunshot \\
\hline Cicadas & Keyboard & Crickets & Glass bursting \\
\hline Knocking & Duck & Bowling pins & Cicadas \\
\hline Guitar & Screaming & Raining & Whistling-human \\
\hline Crickets & Beat box & Bird chirping & Guitar \\
\hline Glass bursting & Burping & Zipper & Coughing \\
\hline Snoring & Raining & Burping & Thunder \\
\hline Waves & Motorcycle & Wind blowing & Helicopter \\
\hline Whistle (tool) & Cat & Oriental bell & Frog \\
\hline Sudden braking-car & Laughing & Train running & Baby crying \\
\hline Dog barking & Vacuum cleaner & Cow & Knocking \\
\hline Gunshot & & Crumpling PET & \\
\hline
\end{tabular}


Figure 1. Distribution of the average environmental sound perception scores of list 1.
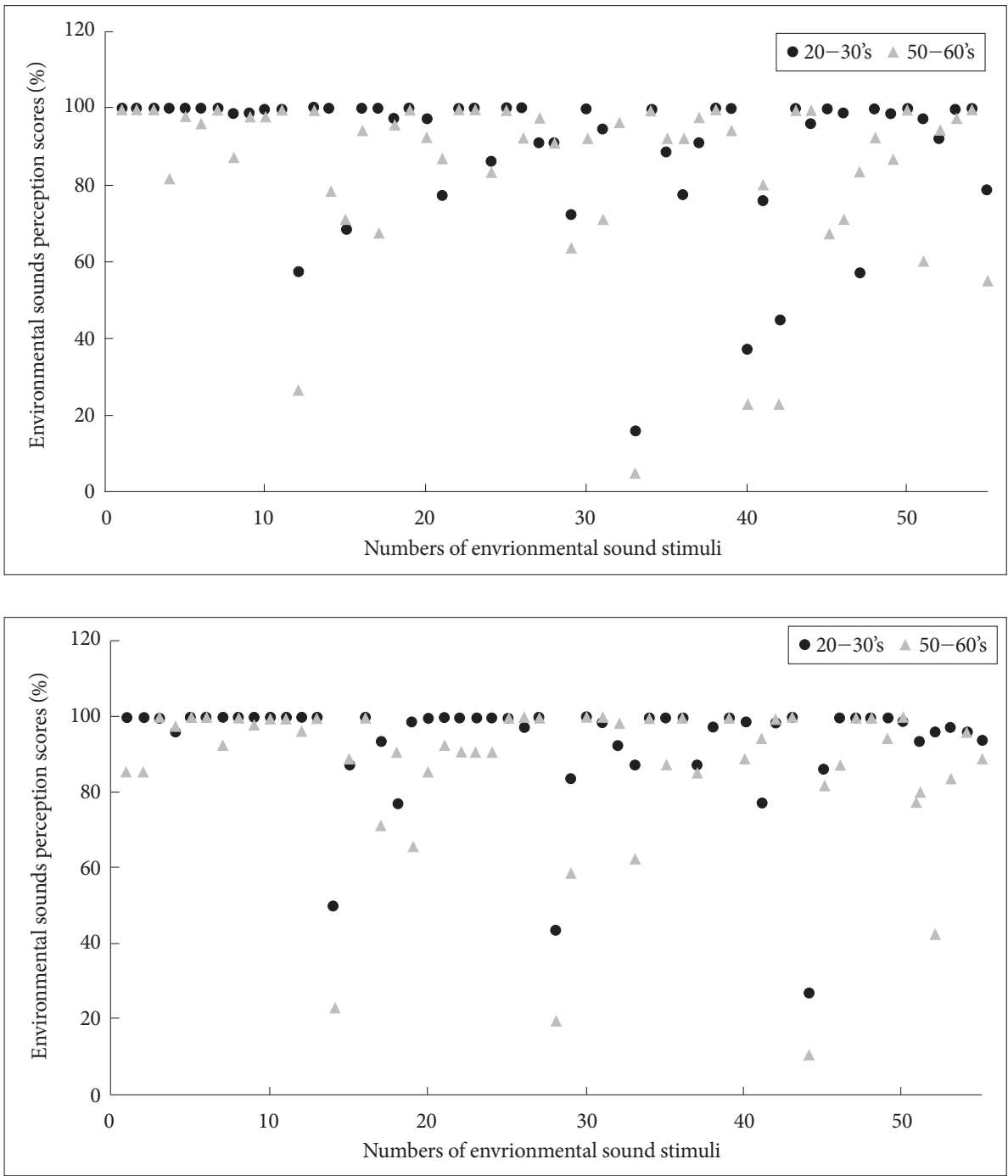

Figure 2. Distribution of the average environmental sound perception scores of list 2.
$95.5 \%$, 목록 2는 $95.8 \%$ 로 나타나서 목록 간의 차이는 없었다 $[t(44)=-0.310, p>0.05]$. 그러나 20 30대는 97.5\%, 50 60대는 $93.7 \%$ 로 나타나 연령대 간에는(유의미한) 차이를 보였다 $[t(43)=$ 3.166, $p<0.01]$.

\section{DISCUSSIONS}

본 연구에서는 난청인이 보청기 또는 인공와우를 착용한 후 청능훈련에 필요한 환경음원을 개발하고자 하였다. 환경음원은 주변에서 흔히 들을 수 있는 여러 가지 환경음 중에서 친숙도와 발생 빈도를 고려하여 55개를 수집한 후 이 음원들이 도구로서 적절한지에 대한 검증을 실시하여 최종적으로 44개를 선정하 였다.

본 연구에서 목록 1과 목록 2의 환경음인지도는 두 목록 모두 50 60대 그룹이 20 30대 그룹에 비해 낮게 나타났다 $(p<0.01)$. Gordon-Salant(2005)의 연구에서 노인은 조용한 곳, 소음, 반

Figure 3에서 최종 선정한 환경음원의 인지도는 목록 1이 
Table 2. The 44 items of environmental sound which were adopted in this study for auditory training

\begin{tabular}{llll}
\hline Doorbell & Chicken & Frog croaking & Glass bursting \\
Train running & Toilet flushing & Wind blowings & Snoring \\
Cow & Car starting & Car horn & Waves \\
Door closing & Bowling pins & Drum & Whistle (tools) \\
Coughing & Dog barking & Baby crying & Sudden braking-car \\
Bird chirping & Whistling-human & Ship whistle & Screaming \\
Siren & Aircraft engines & Crickets & Beat box \\
Horse & Wolf & Keyboard & Burping \\
Clapping & Gunshot & Cicadas & Motorcycle \\
Piano & Camera shutter & Knocking & Cat \\
Phone rings & Thunder & Guitar & Laughing \\
\hline
\end{tabular}

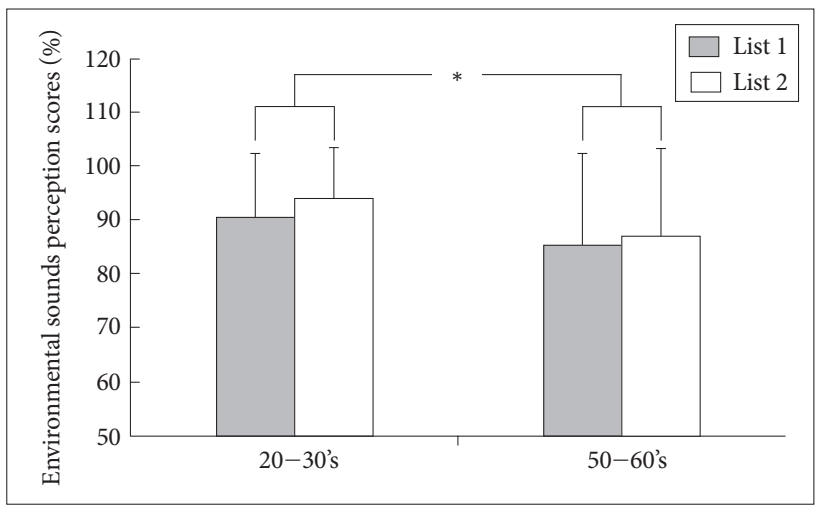

Figure 3. Average environmental sound perception scores by lists and ages. ${ }^{*} p<0.01$.

향음 등에서 음향 정보의 처리에 있어서 어려움을 준다고 하였 는데 본 연구의 50 60대 그룹의 환경음인지도는 연령과 청력역 치가 영향을 준 것으로 볼 수 있다. 하지만 모든 소리를 20 30 대 그룹이 더 잘 인지한 것은 아니었는데 개구리, 귀뚜라미, 오 리 울음소리는 50 60대 그룹의 환경음인지도가 더 높게 나타 났다. 반대로 비트박스, 키보드, 볼링핀 소리의 경우는 20 30대 그룹의 환경음인지도가 더 높게 나타나는 경향을 보였다. 이는 개개인의 환경, 문화, 취미생활 등에 대한 경험의 차이로 인해 환경음인지도의 차이가 발생한 것으로 볼 수 있다.

피검자의 성별에 따라서도 환경음에 대한 인지도의 차이를 살펴볼 수 있었는데, 환경음원 중 총소리의 경우 남성 피검자 는 대부분 단번에 맞히는 반면 여성의 경우 여러 번 반복해서 제시한 후에 인지하는 경우가 다수였고, '폭죽소리', '폭발소리' 등으로 잘못 인지하는 경우도 있었다. 반대로 피아노 그리고 플 루트와 같은 악기 소리의 인지에 있어서는 여성의 경우가 남성 에 비해 더 높게 나타났다.

그리고 기계음이 포함된 항목에서 인지도가 감소하는 점을 확인하였다. 드릴 소리의 경우 인지도가 12 16\%밖에 되지 않 았으며, 피검자들이 제일 혼동하는 소리는 헤어 드라이기 소리 와 청소기 소리였다. 실제 검사 시에도 두 소리를 모두 청소기
소리로 알아듣는 피검자가 많았고, 두 소리를 서로 바꾸어 답 변한 경우도 가끔 있었으며, 그림판을 제시하는 폐쇄형 검사에 서도 정확히 구별해내는 피검자는 소수에 불과했다. 검증 과정 중 환경음원에서 제외한 것은 드릴, 헬리콥터 프로펠러, 청소 기, 헤어드라이기 소리 등이다. 평가 후 피검자들은 기계나 팬 이 돌아가는 소리는 소리 크기만 조금 다르게 느낄 뿐 모두 비 슷한 소리라는 반응을 나타냈다. 악기의 경우 플루트의 소리를 인지하는 데 많은 사람들이 어려움을 보였다. 대부분의 피검자 는 플루트 소리가 관악기의 한 종류라고 인지는 하였지만 정확 히 플루트 소리라고 답하지 못하는 경우가 대다수였다. 이는 피 검자의 인지능력 외에도 플루트가 관악기를 대표하는 데 적합 하였는지를 생각해 볼 필요가 있다.

Shafiro(2008)는 40개의 환경음을 선정하여 각 환경음 당 서로 다른 4 개의 소리를 수집하여 총 160 개의 음원을 훈련용 과 평가용으로 나누어 사용하였다. Shafiro(2008)의 경우가 환 경음 인지능력을 파악하기 위한 평가에 초점을 맞춘 도구의 개 발이었다면 본 연구에서 수집한 환경음원은 청능훈련용이라는 점에서 차이를 갖는다. 평가 방법에서도 두 연구 간에 차이가 있 는데 Shafiro(2008)는 폐쇄형으로 평가를 진행하였고, 본 연구 는 개방형과 폐쇄형 검사를 병행하여 사용하였다. 환경음인지도 에 있어 평가방법은 인지도 결과에 영향을 줄 수 있다. 보기가 제시되는 폐쇄형의 경우 그렇지 않은 경우인 개방형 검사에 비 해 높은 인지도를 나타냈고 편차도 작았다(Inverso \& Limb, 2010; Reed \& Delhorne, 2005). 본 연구에서는 환경음의 검증 시 개방형과 폐쇄형을 혼합하여 사용하였는데, 이는 본 연구의 대상자가 청력손실이 없는 건청의 성인이라는 점과 연구의 목 적이 환경음인지도의 평가가 아닌 새로 개발한 환경음 도구의 검증에 초점을 맞쵰기 때문이다.

본 연구에서는 55 개의 환경음원을 수집한 후 환경음인지도 가 $80 \%$ 이상인 44 개의 환경음원을 최종적으로 선정하였으며, 환경음원의 목록은 같은 내용을 무작위로 배치하여 2 개의 목 록으로 구성하였다. 본 연구에서 개발한 환경음 도구는 청능훈 
련의 기초단계에 사용하거나, 단어 또는 문장에 의한 청능훈련 이 불가능한 경우에 사용할 수 있을 것으로 기대한다. 그러나 향후에는 환경음원에 대한 주파수 및 강도의 분석, 청능훈련 효과의 검증 그리고 문장, 단어 등을 이용한 청능훈련 도구와 의 상관관계 등에 대한 연구가 필요하다. 또한 본 연구에서의 환경음원은 성인을 대상으로 검증을 하였기 때문에 향후에는 아동을 대상으로 한 검증이 필요하며, 필요하다면 아동을 위한 환경음원의 개발이 필요하다. 나아가 $\mathrm{Yu}$ et al.(2014)의 연구에 서도 시도하였듯이 환경음원과 이에 해당하는 그림을 스마트 폰의 어플리케이션으로 개발하여 청능훈련의 흥미를 유발하게 한다면 청능훈련의 효과 또한 높일 수 있을 것으로 기대한다.

중심 단어 : 보청기·청능훈련·환경음·보청기·인공와우.

\section{REFERENCES}

Burk, M. H. \& Humes, L. E. (2008). Effects of long-term training on aided speech-recognition performance in noise in older adults. Journal of Speech, Language, and Hearing Research: JSLHR, 51(3), 759-771.

Cho, Y. Y., Bahng, J. \& Lee, J. H. (2013). Case study of auditory training for an elderly hearing aid user. Audiology, 9(2), 190-194.

Gordon-Salant, S. (2005). Hearing loss and aging: new research findings and clinical implications. Journal of Rehabilitation Research and Development, 42(4 Suppl 2), 9-24.
Inverso, Y. \& Limb, C. J. (2010). Cochlear implant-mediated perception of nonlinguistic sounds. Ear and Hearing, 31(4), 505-514.

Kwon, Y. J. (2014). Effects of 8-week auditory training: Compressed speech and speech in noise (unpublished master's thesis). Hallym University of Graduate Studies, Seoul.

Lee, J. H. \& Kim, J. H. (2011). Comparison of word and environmental sound recognition by cochlear implant and hearing aid users. Audiology, 7(1), 28-39.

Lee, Y. S. (2011). Effects of training on nonsense syllable performance in noise (unpublished master's thesis). Hallym University, Seoul.

Reed, C. M. \& Delhorne, L. A. (2005). Reception of environmental sounds through cochlear implants. Ear and Hearing, 26(1), 48-61.

Shafiro, V. (2008). Development of a large-item environmental sound test and the effects of short-term training with spectrally-degraded stimuli. Ear and Hearing, 29(5), 775-790.

Shafiro, V., Gygi, B., Cheng, M. Y., Vachhani, J., \& Mulvey, M. (2011). Perception of environmental sounds by experienced cochlear implant patients. Ear and Hearing, 32(4), 511-523.

Sweetow, R. W. \& Sabes, J. H. (2006). The need for and development of an adaptive Listening and Communication Enhancement (LACE) program. Journal of the American Academy of Audiology, 17(8), 538-558.

Sweetow, R. W. \& Sabes, J. H. (2010). Auditory training and challenges associated with participation and compliance. Journal of the American Academy of Audiology, 21(9), 586-593.

Yeo, S. H., Bahng, J., \& Lee, J. H. (2014). Efficacy of auditory training using sentences in noise for hearing aid users. Audiology, 10(1), 65-75.

Yu, J., Chun, H., Song, C. G., \& Han, W. (2014). Case study of speech perception enhancement in hearing-impaired adult by auditory training program of mobile device. Audiology, 10(2), 158-168. 
APPENDIX

The final items of environmental sound which were selected in this study for auditory training (English into Korean)

\begin{tabular}{llll}
\hline Doorbell & 초인종소리 & Frog croaking & 개구리 울음소리 \\
Train running & 기차 달리는 소리 & Wind blowings & 바람부는 소리 \\
Cow & 소 울음소리 & Car horn & 자동차 경적소리 \\
Door closing & 문 닫는 소리 & Drum & 드럼 연주소리 \\
Coughing & 기침소리 & Baby crying & 아기 울음소리 \\
Bird chirping & 새 지저귀는 소리 & Ship whistle & 뱃고동소리 \\
Siren & 사이렌소리 & Crickets & 귀뚜라미 울음소리 \\
Horse & 말 울음소리 & Keyboard & 키보드 치는 소리 \\
Clapping & 박수소리 & Cicadas & 매미 울음소리 \\
Piano & 피아노 연주 & Knocking & 노크소리 \\
Phone rings & 전화 벨소리 & Guitar & 기타 연주소리 \\
Chicken & 닭 울음소리 & Glass bursting & 병 깨지는 소리 \\
Toilet flushing & 변기 물 내리는 소리 & Snoring & 코고는 소리 \\
Car starting & 자동차 시동 거는 소리 & Waves & 파도소리 \\
Bowling pins & 볼링 핀 넘어지는 소리 & Whistle (tool) & 호루라기소리 \\
Dog barking & 개 짖는 소리 & Sudden braking-car & 자동차 급정거하는 소리 \\
Whistling-human & 휘파람소리 & Screaming & 비명소리 \\
Aircraft engines & 비행기 엔진소리 & Beat box & 비트박스소리 \\
Wolf & 늑대 울음소리 & Burping & 트림소리 \\
Gunshot & 총소리 & 카메라셔터소리 & 오토바이소리 \\
Camera shutter & 천둥소리 & Cat & 고양이 우는 소리 \\
Thunder & & aㅜㅅ음소리 \\
\hline
\end{tabular}

